\title{
Cultural Policy in Germany - Chance for Change?
}

\author{
Martin Lücke \\ Macromedia University of Applied Sciences \\ m.luecke@macromedia.de
}

\begin{abstract}
The Corona pandemic is still ongoing and has changed almost all areas of economic, social and cultural life-perhaps even lastingly, it is not yet possible to say. The music sector, in all its diversity, also suffers from the current restrictions. In this statement dealing with cultural policy in Germany, I discuss the need to distribute public funding for culture differently. In the last few months, it has become clear that it is above all the non-publicly financed free popular culture scene that suffers most from the restrictive effects (for example, bans on appearances). The publicly funded (music-)cultural sector, on the other hand, can continue to plan the future-without any guarantee as to how it will run. The Corona pandemic should have been a time to bring institutional and independent scenes closer together in order to create something new both artistically and organizationally.
\end{abstract}

KEYWORDS: cultural policy, cultural sector, public funds, Corona pandemic

\section{Initial Situation}

The year 2020, marked by the Corona pandemic, will most certainly be remembered by everyone, so remarkable were (and still are) the restrictions that almost everyone has been experiencing for months in very different areas of life. Corona has quickly evolved from an epidemic to a pandemic, and most countries all around the world are experiencing high numbers of infections as well as high death rates. Germany, the country on which the following statement will focus, is at this moment (January 2021) in the middle of the so-called second wave of the pandemic: more than 20,000 infected people daily, more than 1,000 deaths daily, hospitals and their staff are suffering from permanent overload. The political leadership of the country, the German government under Chancellor Angela Merkel and the governments of the sixteen federal states, are trying to contain the further spread of the virus with more or less coordinated measures (for example, with contact restrictions) — so far without much success. But there has also been positive 
news over the last few weeks: never before in human history have several vaccines been developed within such a short time, and in the meantime, vaccination against the Coronavirus has begun. But it is already foreseeable that this process will take months. Therefore, it will hardly be possible to speak of "normality" in the not too distant future. In my statement, I will discuss the impact of the current pandemic on the (German) cultural scenes, focusing on cultural institutions funded by the state and asking whether the crisis could not also be seen as an opportunity for a radical change in cultural funding.

\section{Cultural Funding in Germany - An Overview}

In order for international readers to understand the further explanations and ideas more easily, a brief digression into the German cultural funding system is necessary. Germany has an extensive public system of cultural funding. According to the latest statistics (Statistische Ämter 2020), the state (for example, the Federal Government, the sixteen states and the several hundred communities) provided 11.4 billion Euros to the cultural scenes in 2017. In simple mathematical terms, this is about 140 Euros per inhabitant. In order to better understand this figure: public cultural funding represents 0.35 per cent of the Gross National Product (GNP) or respectively 1.77 per cent of the total public budget. The main share of this funding is taken over by the sixteen federal states and the communities. The reason for this lies in the existing federal system. One of the guiding principles is: culture is a federal-state matterjust like education, but that's a completely different story. Other funding instruments are also known and used in Germany: endowments, cultural sponsoring, fundraising, crowdfunding, and others. But extrapolated, these funds represent a maximum of ten per cent of public cultural funding.

On the basis of this relatively high level of state cultural funding, a large institutional cultural scene exists comprising nearly 130 classical orchestras, more than eighty opera houses, hundreds of theatres and museums, and much more. One goal of German cultural policy is the (more or less) free participation of cultural opportunities, which is to be realized, among other things, through low admission fees. For this reason, the self-financing ratio of German cultural institutions (depending on the location, the specific cultural sector, etc.) is around ten to forty per cent. A large part of the costs of running (institutional) cultural operations is therefore financed by public funding.

\section{Corona Aid - but Only for a Few?}

Especially in the first weeks of the Corona pandemic and the consequent shutdown beginning mid-March 2020, there was a lot of information about culture on the various media channels; no concerts, no operas, no theatre performances, closed museums, artists of all disciplines without engagements, the list could be extended. The resulting financial problems for cultural workers, cultural institutions, and cultural businesses were obvious to everyone. Quickly, very quickly, and this is pointed out with full admiration, various aid programs were initiated to soften the effects of the shutdown financially. However, these programs were rarely targeted at the so-called independent cultural scene, as only operating expenses could be covered, but not private expenses such as rent. But it continued: in the national economic recovery package passed at the beginning of June 2020, one billion Euros were also promised to culture. But even that was mainly for cultural institutions and 
companies - and not for the solo self-employed, who are important for the diversity of culture as numerous as they are. Only the so-called November aid, which was released at the beginning of the second lockdown at the end of 2020, also benefited solo, self-employed people from the cultural sector. Definitely, this was a learning effect on the side of the legislative authorities, a positive aspect in this difficult time.

\section{A Small Glimmer of Hope: Culture Goes Digital!}

Within a very short time, it became clear who, or which institutions had already embraced the topic of digitalization before Corona. Concerts and theatre productions were suddenly freely available on the web if they had been produced in advance. Classical superstars like pianist Igor Levit, a perfect example of selfstaging on social media, played Beethoven every evening at 7 p.m. on Twitter for weeks - matching the Beethoven Jubilee.

Numerous artists, mostly of non-subsidized popular arts, have also tried to stay present for their audience through various online activities, including online concerts. Clubs streamed to reach their target audience at least at home-and to receive donations. All these activities were and are certainly useful in the current situation. However, only afterwards will it become clear whether these attempts were also successful in terms of fan loyalty. Certainly, financial losses cannot be compensated for by this. But whether subsidized or not: culture was still present to its existing audience (and perhaps also won over new listeners for the post-Corona era), just conveyed differently, digitally; but the social exchange, the direct experience was missing, of course.

\section{A Long-Overdue Discussion}

Numerous topics can be discussed in this context (a huge task for the future): whether culture is really systemically essential, whether the funds that the public sector has made available are really sufficient, and so on. And here we are faced with a problem that exists not only since Corona. But in this situation, another crucial topic must be added to the discussion list: the allocation of public cultural funds at the various levels of government relevant to culture.

Which cultural participant gets what? Let us focus on the municipal level: the majority of the available funds are allocated to (only) a few institutions. In terms of their existing cost structure (due to their high personnel costs), these are primarily music theatres, orchestras, performing arts theatres, museums, and beyond that many more. Each of these institutions has its own right to exist. Each of these institutions employs hundreds of people. Many of these institutions offer top-class performances, are known beyond regional borders, and attract culture enthusiasts from abroad. But the fact remains: money that has been spent once on one of these large, expensive flagship institutions cannot be spent a second time. But culture is more diverse than the distribution of municipal cultural funding all too often suggests. I will illustrate this with an example: the city of Bochum, in the middle of the so-called Ruhr area between Essen and Dortmund, with approximately 380,000 inhabitants, formerly characterized by the coal, steel and automobile industries (Opel), in a region with probably the highest institutional, cultural density in Germany, has a cultural budget of approximately seventy-five million Euros, five per cent of the total municipal budget: Only eight institutions-the local theatre (Schauspielhaus Bochum), the Bochum Symphony Orchestra (Bochumer 
Symphoniker), the music school, the municipal library, the municipal archive, the adult education center, the Bochum Art Museum and the planetarium-receive about fifty million Euros of this budget. In other words, only a tiny fraction is left for the "rest" (independent theatres, galleries, independent music groups, the whole rock, jazz and pop scene, clubs, sociocultural and so on). In other cities (the exception proves the rule), the picture is not much different.

\section{Repetition Consolidated: Culture is More than High Culture!}

No one denies the importance of music schools, libraries or adult education centers. Institutions like these are particularly important in terms of cultural and educational participation for all. But there is more than theatre or classical music culture, and this 'more' is not a leftover, but in fact, an important part of cultural life: independent scenes, sociocultural scenes, urban-creative scenes, festivals, art projects, and many more. This is the moment for a broad culture and its incredibly diverse offer, which - and one must be so honest here - reaches everyone, and especially the non-cultural citizens much more often than institutionalized and subsidized so-called high culture.

Let's go back to the still existing Corona restrictions. Should everything continue as before? Should the large cultural institutions get most of the funding, the independent scene the miserable rest? During the first and partly also during the second lockdown, theatres and orchestras applied for short-time work (the state takes over up to seventy-six per cent of the employee's salary)_a bitter financial loss for the staff on and behind the stage. Of course. But the financial loss was compensated for by the institution so far that, in the end, there was a tolerable salary loss of five per cent.

The independent scenes, on the other hand, the freelance artists, the solo selfemployed, there are many of them in the cultural sector, had and still have no significant income from their directly employed (cultural/artistic) work. Moreover, as already mentioned, many state support programs are not designed for this freelancers group. And even more dramatic: when and if there will be a return to normal business for this group is still unclear. In contrast, the institutions already went into limited normal operation during the summer, pushing ahead their plans for the 2020/2021 season like the virus no longer existed. Business as usual?

For critical outsiders, one question always remained: what does a (music) theatre want to perform if the current hygiene rules are strictly followed in front of, on, and behind the stage? And what does a classical orchestra want to play under these conditions?

\section{It's Simple: Time to Make a Change}

The current restrictions offer the opportunity to try something new if all those involved were willing to co-operate. Why should we continue to think in terms of the two antipodes-publicly funded institutions here and the independent scene there? Why not finally have a real, close, collaborative and financially secured cooperation that benefits cultural workers and the public overall?

It might have been clear to everyone at the beginning of the crisis that theatres and orchestras would not be able to finish the season completely. Instead, most institutions planned the 2020/2021 season, but the hygiene regulations in force caused absurd plans, such as removing entire rows of chairs from the theatres to fill them to half capacity, against all economic logic... And no one asks themselves whether the typical audience (beware: risk group) will even come? Since November 
2020, it has become clear that a major part of the 2020/2021 season will disappear due to another lockdown. That's why I demanded very early in several (undocumented) conversations with municipal cultural leaders during the first lockdown that we should rather look at the 2021/2022 season as a new beginning. Because more important, and really exciting, is the in-between that would have been created: I imagine a creative season, an experimental season, a season that is free of artistic and political obligations, a time in which utilization, among other things, does not play a role. It seems so obvious to use this period to make a fundamental change: why don't the so far publicly funded institutions take the time to experiment now, in a year when restrictions on public life will continue to exist? And not alone, not in the well-known framework, with well-known people, but with the local scene, the whole cultural scene, all genres, all shades, all levels of professionalism! The money for these experiments exists because institutions save money when they don't hire top-class performers from abroad (who don't travel because of Corona). This money could better be invested in cultural togetherness.

\section{Free Space Without Pressure}

Is there anything to be gained from this? We do not know. The outcome of such a creative season is uncertain; things can go wrong-whatever that means. But let's be honest, we are in extraordinary times; for almost all of us, it is the first pandemic we have lived through. But what is normal? It was and is a time for changes that you can create yourself. It is an opportunity because things can be different; new points of interaction can arise between cultural groups that previously did not know or even opposed each other. This togetherness has the potential to give broad-based culture new impetus, to give it a prominent podium, to strengthen its selfconfidence, to sharpen its artistic profile-and at the end of the day, it can simply be fun for everyone! Ideally, this will also benefit the existing institutions, whether independent or public, the numerous solo artists in the region, and in the end, the audience, who can look forward to something special and unique for an entire year in a world we cannot yet foresee. What do you like more? Uniqueness in the uniqueness of the pandemic.

\section{Time for Dreaming}

However, the scenario described here has remained utopian. Public institutions continue to plan as before. The existing shutdown may reduce revenues, but the basic financial support remains unchanged. The many independent cultural workers, also involved in the institutions, are losing more and more of their basis for life.

But dreaming is allowed, also in the cultural sector, and sometimes wishes would become true. This requires courage and farsightedness - things that are often attributed to cultural workers. Courage and vision must also be practiced, and will certainly fall on fertile (recipient) ground.

2020 and 2021 in retrospect may only be the "Corona years". But perhaps they will also be a turning point in cultural policy-the beginning of the end of a few, highly subsidized cultural flagships. Instead, the beginning of a cooperation of the entire cultural scene to act together in all its diversity. Ideally, completely new artistic flagships will be created in the process.

The money is there. 
Only the courage is lacking!

\section{References}

Statistische Ämter. 2020. Kulturfinanzbericht 2020.

https://www.destatis.de/DE/Themen/Gesellschaft-Umwelt/Bildung-ForschungKultur/Kultur/Publikationen/Downloads-Kultur/kulturfinanzbericht1023002209004.pdf;jsessionid=AD45A176A214C4C9DB6E00F618247C5D.in ternet8731? blob=publicationFile

Accessed: 7 January 2021. 